\title{
Activation of the ribosomal protein L13 gene in human gastrointestinal cancer
}

\author{
TOSHIHISA KOBAYASHI ${ }^{1}$, YASUSHI SASAKI ${ }^{1,2}$, YUICHIRO OSHIMA $^{2}$, \\ HIROYUKI YAMAMOTO $^{1}$, HIROAKI MITA ${ }^{1,2}$, HIROMU SUZUKI ${ }^{1}$, MINORU TOYOTA ${ }^{1}$, \\ TAKASHI TOKINO $^{2}$, FUMIO ITOH ${ }^{3}$, KOHZOH IMAI $^{1}$ and YASUHISA SHINOMURA $^{1}$ \\ ${ }^{1}$ First Department of Internal Medicine and ${ }^{2}$ Department of Molecular Biology, \\ Cancer Research Institute, Sapporo Medical University School of Medicine, S-1, W-17, Chuo-ku, \\ Sapporo 060-8556; ${ }^{3}$ Division of Gastroenterology and Hepatology, Department of Internal Medicine, \\ St. Mariana University School of Medicine, 2-16-1 Sugao, Miyamae-ku, Kawasaki 216-8511, Japan
}

Received January 3, 2006; Accepted February 12, 2006

\begin{abstract}
Although ribosomal proteins are major components of ribosomes, recent data have shown them to have extraribosomal functions apart from ribosome and protein biosynthesis. In our earlier study, we showed that ribosomal protein L13 mRNA was up-regulated in response to DNA damage in hamster cells. We report here that L13 expression is up-regulated in human gastrointestinal cancers. We also examined the biological role of L13 on human cancer cells. Knocking down L13 expression using small interfering RNA (siRNA) resulted in drastic attenuation of cancer cell growth with significant G1 and G2/M arrest of the cell cycle. Moreover, L13 siRNA significantly enhanced the cellular sensitivity to certain DNA damaging agents and, concordantly, L13overexpressing cells demonstrated greater chemoresistance compared to parent cells, suggesting an inverse correlation between L13 expression and chemosensitivity. By using semiquantitative RT-PCR, we analyzed expression of L13 in freshly resected cancer tissue of the stomach, colorectum and liver. Up-regulation of L13 mRNA expression was observed in $10(28 \%)$ of 36 gastric, $19(41 \%)$ of 46 colorectal and $5(20 \%)$ of 25 liver cancer tissue samples compared to adjacent normal tissue samples. We also found that increased expression of the
\end{abstract}

Correspondence to: Dr Yasushi Sasaki, Department of Molecular Biology, Cancer Research Institute, Sapporo Medical University School of Medicine, S-1, W-17, Chuo-ku, Sapporo 060-8556, Japan E-mail: yasushi@sapmed.ac.jp

Abbreviations: $\mathrm{BBC} 1$, breast basic conserved 1; $\mathrm{LOH}$, loss of heterozygosity; RT-PCR, reverse transcriptase/polymerase chain reaction; DOX, doxorubicin; VP-16, etoposide; CDDP, cisplatin; DOC, docetaxel

Key words: ribosomal protein L13, breast basic conserved 1, gastrointestinal cancers, chemosensitivity, siRNA
L13 gene correlated with clinical staging in gastric cancers. The results of this study suggest that L13 plays an essential role in the progression of some gastrointestinal malignancies.

\section{Introduction}

Gastrointestinal cancers are quite common malignancies and a major cause of cancer-related deaths throughout the world (1). Early-stage cancer patients are often asymptomatic, resulting in delayed diagnosis and detection only at advanced stages. Additionally, it is well recognized that most patients who undergo surgery for gastrointestinal cancers remain at high-risk for local or systemic relapse. Thus, chemotherapy is a common treatment modality for gastrointestinal cancer (1). However, cancer chemotherapy is not always clinically effective because cancer cells can acquire a drug-resistant phenotype during carcinogenesis through a variety of mechanisms $(2,3)$. Understanding the molecular basis for the sensitivity to chemotherapeutic drugs is expected to improve the efficacy of the drugs and ameliorate severe side-effects in addition to providing useful insights for the optimization of cancer treatment (3-5).

To maintain the fidelity of chromosome segregation, eukaryotes have a feedback control mechanism, often referred to as a cell cycle check-point, that arrests the cell cycle in the G1 or G2 phases to allow repair of a damaged template before replication. The activation of cell cycle check-points plays an important role in the DNA damage response, and their impairment contributes directly to the sensitivity to chemotherapeutic drugs (6-9). For example, the p53 tumor suppressor participates in the cellular response to DNA damage by regulating cell cycle progression, DNA repair and apoptosis. Indeed, disruption of p53 makes cancer cells more susceptible to chemotherapy-induced apoptosis (10-12). We recently reported on the roles of CHFR [check-point with fork head-associated (FHA) and ring finger] and T-fimbrin in cellular sensitivity to chemotherapeutic drugs (13-15). However, the presence or alteration of a single factor is generally not predictive of the sensitivity/resistance status of cancer cells. 
Using differential display, we have previously isolated genes differentially expressed in Chinese hamster ovary cells after treatment with DNA damaging agents $(16,17)$. One of several clones obtained revealed homology to the gene for ribosomal protein L13, encoding a 211-amino-acid protein with a calculated molecular weight of 20,692. Recent data have shown that ribosomal proteins may have extraribosomal functions apart from ribosome and protein biosynthesis $(18,19)$. For example, the gene encoding ribosomal protein S19 is mutated in approximately $25 \%$ of patients with DiamondBlackfan anemia, which is a rare congenital erythroblastopenia (20). Also, a differential expression of specific ribosomal protein genes was reported earlier as general characteristics of various tumor cell types (21-25).

In the present study, we focused on ribosomal protein L13 for its potential role in tumor biology and found that L13 may play a significant role in the proliferation or viability of human gastrointestinal cancer cells. We also show an inverse correlation between L13 expression and chemosensitivity. Our data suggest that the status of L13 expression may be a useful molecular marker for predicting the responsiveness of cancer cells to treatment with chemotherapeutic drugs.

\section{Materials and methods}

Tissue and cell lines. Nine gastric cancer cell lines (MKN7, MKN28, MKN45, MKN74, KATOIII, AZ521, NUGC2, NUGC3 and NUGC4), 12 colorectal cancer cell lines (SW480, SW948, HCT116, HCT15, DLD1, LoVo, HT29, RKO, WiDr, Colo201, Colo205 and Colo320), 9 liver cancer cell lines (Huh6, Huh7, HLE, HLF, PLC/PRF5, JHH4, Hep3B, CHC4 and $\mathrm{CHC} 12$ ), and $\mathrm{CHO}$ cells were obtained from either the American Type Culture Collection (Manassas, VA) or the Japanese Collection of Research Bioresources (Tokyo, Japan). All cells were cultured under conditions recommended by their respective depositors. DOX, VP-16, CDDP and DOC were purchased from Sigma (Saint Louis, MO).

Tumor tissue and adjacent non-tumor tissue were obtained from 36 patients with gastric adenocarcinomas, 46 patients with colorectal adenocarcinomas and 25 patients with hepatocellular carcinomas undergoing surgical treatment at the Sapporo Medical University Hospital as described previously $(26,27)$. None had received previous chemotherapy. Informed consent was obtained from each subject, and the experiments were approved by the institutional review committee. Each tissue specimen was divided into two pieces after resection. For total RNA extraction, one sample was immediately frozen in liquid nitrogen at the time of surgery and maintained at $-80^{\circ} \mathrm{C}$ until use. The other sample was processed for pathological examination using haematoxylin and eosin staining for the evaluation of the tumor cell content. Only specimens containing more than $80 \%$ tumor cells were used for analysis. All of the tumors were classified according to the TNM classification system of the Union International Contre Cancer (28). Histologically, according to the classification of Lauren (29), gastric cancers were also classified into intestinal and diffuse types. Staging of colorectal cancers was also used for Duke's classification (30).

Sequencing. Total RNA was extracted from cell lines and tissue using Trizol reagent according to instructions from the manufacturer (Invitrogen, Carlsbad, CA). cDNAs were obtained by reverse transcription using a SuperScript preamplification system (Invitrogen) with $2 \mu \mathrm{g}$ of total RNA. The entire coding region of the L13 gene was amplified by PCR with primers 5'-TTTCCGCTCGGCTGTTTT-3' (sense) and 5'-CGACTGATTCCAAGTCCCC-3' (antisense), as described previously (31). After amplification, gel-purified PCR products were directly sequenced using an Applied Biosystems model 373 S sequencer and a Thermo Sequenase dye terminator cycle sequencing pre-mix kit (Amersham Pharmacia Biotech, Buckinghamshire, UK). Nucleotide sequencing was performed in sense and antisense directions with the primers used for PCR and internal primers.

Semi-quantitative RT-PCR and Northern blot analysis. For semi-quantitative RT-PCR analysis, cDNAs were synthesized as described above. The RT-PCR exponential phase was determined on 20-30 cycles to allow semi-quantitative comparisons among cDNAs from identical reactions. The PCR conditions involved an initial denaturation step at $94^{\circ} \mathrm{C}$ for $2 \mathrm{~min}$, followed by 30 cycles (for L13) or 25 cycles (for GAPDH) at $94^{\circ} \mathrm{C}$ for $30 \mathrm{sec}, 58^{\circ} \mathrm{C}$ for $30 \mathrm{sec}$ and $72^{\circ} \mathrm{C}$ for $1 \mathrm{~min}$. Oligonucleotide primer sequences were as follows: L13 sense, 5'-GCATTTC TGTGGATCCGAGGAG-3'; L13 antisense, 5'-CGACTGAT TCCAAGTCCCC-3'; GAPDH sense, 5'-ACCACAGTCCAT GCCATCAC-3'; and GAPDH antisense, 5'-TCCACCACCC TGTTGCTGTA-3'. The PCR products were visualized by electrophoresis on $1.5 \%$ agarose gels. For Northern blot analysis, total RNA (10 or $20 \mu \mathrm{g}$ ) was electrophoretically separated on a $1 \%$ agarose gel containing $2.2 \mathrm{M}$ formaldehyde and blotted onto a nitrocellulose membrane (Schleicher \& Schuell, Dassel, Germany). RNA was visualized with ethidium bromide to ensure that it was intact and loaded in similar amounts and to confirm proper transfer. Hybridization was performed as described previously (32). cDNA probes for L13 were amplified by RT-PCR and sequenced to verify their identity. For measurement of mRNA stability, $50 \%$ confluent cells were treated with $25 \mu \mathrm{M}$ VP-16 for $2 \mathrm{~h}$ to induce DNA damage or were left untreated (for controls). Actinomycin D $(10 \mu \mathrm{g} / \mathrm{ml})$ was added to the culture $12 \mathrm{~h}$ later to inhibit further transcription. Cells were harvested at different time-points and total RNA was extracted for Northern analysis.

RNA interference (RNAi). siRNAs (Dharmacon Research, Lafayette, $\mathrm{CO}$ ) for L13 with the following target sequence were used: si-L13-1, 5'-AACGGUUCGGUACCACACGAA3'; and si-L13-2, 5'-AAGGAAGCCGCAGAACAGGAU-3'. A negative control siRNA termed Non-specific Control VII (target sequence: 5'-NNACTCTATCGCCAGCGTGAC-3') was also purchased from Dharmacon and has no significant homology to any known human sequence. Cells $\left(5 \times 10^{6}\right)$ were transfected with 250 pmol of L13-specific and control siRNA oligoduplexes by using the Amaxa Nucleofector Device (program O-17, kit T for NUGC4; and program D-32, kit V for HCT116) following the manufacturer's instructions for adherent cells (Amaxa, Cologne, Germany). At the indicated time-points after the transfection, cells were used for RT-PCR, cell viability assays and flow cytometry. Transfection efficiency ( $75 \%$ at $24 \mathrm{~h}$ post-transfection) was monitored by using fluorescein-labeled dsRNAi and immunofluorescence microscopic 
Table I. Polymorphisms of the L13 gene in gastrointestinal cancer cell lines.

\begin{tabular}{lccccc}
\hline Base position & Polymorphism & Amino acid change & Stomach & Colon & Liver (\%) \\
\hline 144 & $\mathrm{~T} \rightarrow \mathrm{G}$ & No change & $2 / 9(22)$ & $9 / 12(75)$ & $2 / 9(22)$ \\
192 & $\mathrm{C} \rightarrow \mathrm{T}$ & No change & $0 / 9(0)$ & $0 / 12(0)$ & $2 / 9(22)$ \\
385 & $\mathrm{G} \rightarrow \mathrm{A}$ & Ala $\rightarrow \mathrm{Thr}$ & $0 / 9(0)$ & $2 / 12(17)$ & $0 / 9(0)$ \\
\hline
\end{tabular}

analysis. L13 mRNA levels were determined by RT-PCR analysis as described above.

Plasmid constructs and transfection. The entire coding region of the human L13 cDNA was subcloned into mammalian expression vector, pcDNA3.1/His (Invitrogen), using EcoRI sites. The plasmid construct was sequenced and named pcDNA/ His-L13. For plasmid transfection, cells were plated at $5 \times 10^{5}$ cells in 60-mm dishes 1 day before transfection. Transfections were performed using Lipofectamine 2000 (Invitrogen) according to the manufacturer's instructions with $2 \mu \mathrm{g}$ of the L13 expression plasmid (pcDNA/His-L13) or an equal amount of empty vector plasmid (mock). Two days later, transfection was repeated in order to maintain His-L13 expression long enough for the proliferation assay. Expression of His-L13 was checked by immunoblot analysis as described previously (33).

Cell viability assay. Proliferation of transfected cells was analyzed by using the trypan blue exclusion method and a hemocytometer during the time course, as described previously (33). To evaluate the chemosensitivity of cells to some DNA damaging agents, we determined proliferation rates by measuring the uptake of tritium thymidine using the 3-(4,5dimethylthiazol-2-yl)-2,5-diphenyltetrazolium bromide (MTT) assay. Transfected cells were seeded in each well of 96-well plates at $5 \times 10^{3}$ cells per well, and subsequently treated with DOX, VP-16, CDDP and DOC, respectively. After 48-h incubation, MTT assay was performed in triplicate using a Cell Counting kit-8 (Dojindo, Tokyo, Japan) according to the manufacturer's instructions. The colorimetric readout in this assay reflects the number of metabolically active mitochondria, and hence viable cells, in a given well. Values were normalized relative to cells not treated with chemotherapeutic agents. Data shown are representative of three independent experiments. The colony formation assay was described previously $(13,15,34)$. Briefly, cells were transfected with the L13 expression plasmid (pcDNA/His-L13) or the empty vector plasmid as described. The transfected cells $(5,000$ cells $/ 6-\mathrm{cm}$ plate $)$ were treated with $25 \mu \mathrm{M}$ VP-16 for $2 \mathrm{~h}$. Cells were then rinsed and maintained in medium. After 2 weeks, colonies were fixed and stained with Giemsa stain, and surviving fraction was counted.

Cell cycle analysis. The cell cycle was examined using FACS analysis. Cells were harvested and fixed in $70 \%$ ethanol. The fixed cells were then stained with propidium iodide $(50 \mu \mathrm{g} /$ ml) after treatment with RNase $(100 \mu \mathrm{g} / \mathrm{ml})$. The stained cells were analyzed for DNA content by fluorescence-activated cell sorting (FACS) in a FACScalibur (Becton-Dickinson Instrument, San Jose, CA). Cell cycle fractions were quantified using CellQuest (Becton-Dickinson).
In vivo tumorigenicity assay. All animals were maintained and all animal experiments were conducted according to the principles enunciated in the Guide for the Care and Use of Laboratory Animals prepared by the Office of the Prime Minister of Japan. For the tumorigenicity assay, HCT116 colorectal or NUGC4 stomach cancer cells were transfected with either si-L13-2 or si-cont. After $24 \mathrm{~h}$, cells were harvested by trypsinization, washed in PBS and counted by trypan blue exclusion staining. Viable cells $\left(2 \times 10^{6}\right.$ cells in $\left.200 \mu 1\right)$ were then injected subcutaneously (s.c.) into the right flanks of female BALB/c nude mice, 4-6 weeks of age. Seven mice were used for each treatment group. Tumor formation in mice was observed weekly for up to 5 weeks. The tumor volume was calculated using the equation, $\mathrm{V}\left(\mathrm{mm}^{3}\right)=\mathrm{axb}^{2} / 2$, where a is the largest dimension and $\mathrm{b}$ is the perpendicular diameter.

Statistical analysis. The relationship between the expression of the L13 gene and clinicopathological characteristics in gastrointestinal malignancies was examined by the $\chi^{2}$ test or Fisher's exact test. P-values $<0.05$ were regarded as statistically significant.

\section{Results}

Mutational analysis of the L13 gene in gastrointestinal cancer cell lines. We previously demonstrated elevated levels of L13 transcripts in CHO cells after treatment with DNA damaging agents, suggesting that L13 is a stress-inducible gene. Alternatively, L13 has been reported as the breast basic conserved 1 (BBC1) gene, which was expressed in benign fibroadenomas at higher levels than in malignant breast tumors. Mutations of the L13 gene were observed at a lower incidence in human prostate cancers (35). We have first examined the mutational status of L13 cDNA in 9 gastric cancer cell lines, 12 colorectal cancer cell lines and 9 liver cancer cell lines. However, no mutations in the L13 gene were detected by direct sequencing. As shown in Table I, three polymorphisms were identified. Two of these did not result in amino acid changes, $144 \mathrm{~T} \rightarrow \mathrm{G}$ and $192 \mathrm{C} \rightarrow \mathrm{T}$. Only one base substitution, nucleotide $385 \mathrm{G} \rightarrow \mathrm{A}$, caused an amino acid substitution at codon 129 from Ala $\rightarrow \mathrm{Thr}$, but this is a known polymorphism that was described in the previous paper (31). Our results indicate that L13 mutations are rare in human cell lines derived from gastrointestinal cancers.

Stability of L13 mRNA after DNA damage. We then examined whether L13 is activated in human cancer cells in response to DNA damage. Expression of L13 was determined by Northern blot analysis in NUGC4 human stomach cancer cells. As a result, we found that L13 transcript levels were increased by 


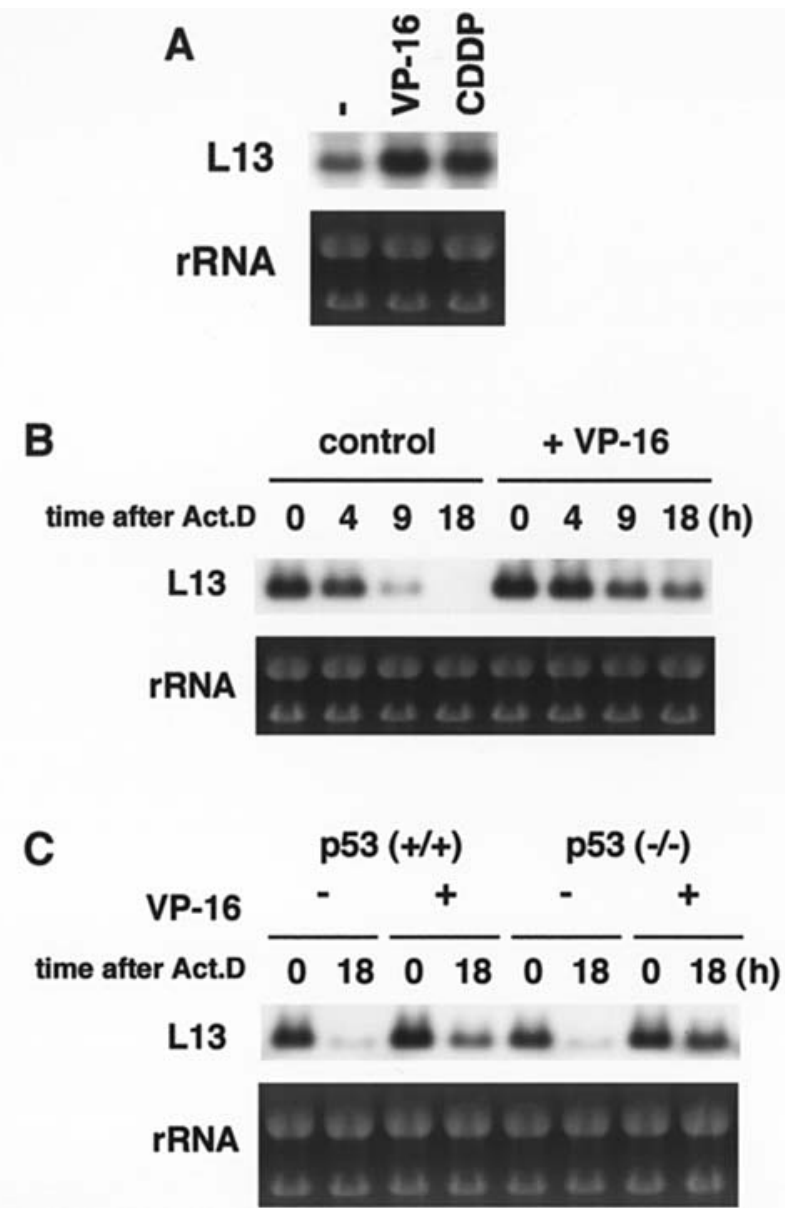

Figure 1. Expression of the L13 gene is induced after DNA damage. (A) NUGC4 human stomach cancer cells were treated with $25 \mu \mathrm{M}$ VP-16 or $50 \mu \mathrm{M}$ CDDP for $2 \mathrm{~h}$. Total RNA was prepared from the cells at $24 \mathrm{~h}$ after treatment, and $10 \mu \mathrm{g}$ of total RNA was loaded in each lane. The blot was hybridized with human L13 cDNAs. Equal loading of total RNA was confirmed by ethidium bromide staining of rRNA. (B and C) Effect of VP-16 treatment on L13 mRNA stability. NUGC4 cells (B) or HCT116 (p53 $3^{+/+}$) and HCT116 (p53 ${ }^{-/-}$) cells (C) were incubated with or without $25 \mu \mathrm{M} \mathrm{VP}-16$ for $2 \mathrm{~h}$. All cultures then received $10 \mu \mathrm{g} / \mathrm{ml}$ actinomycin D (Act. D). RNA samples were collected from the cultures at various times (0-18 h) after Act. $\mathrm{D}$ addition. RNAs were analyzed for L13 mRNA stability by using Northern blotting.

3- and 2.6-fold in response to VP-16 and CDDP, respectively (Fig. 1A). Altered mRNA stability has been demonstrated to be an important mechanism in the regulation of cellular growth control. We, therefore, determined the stability of L13 mRNA following DNA damage. NUGC4 cells were treated with $25 \mu \mathrm{M} \mathrm{VP}-16$ for $2 \mathrm{~h}$ or were left untreated (for controls). Twelve hours later, cultures received the RNA synthesis inhibitor, actinomycin D, to inhibit further transcription. RNA samples isolated from the cells at various times after actinomycin D treatment were tested for L13 expression by Northern blot analysis. As shown in Fig. 1B, after VP-16 treatment, L13 mRNA showed a dramatic increase in stability compared to that in untreated growing cells. These results suggest that L13 induction may result, at least in part, from increased transcript stability after DNA damage.

Because the tumor suppressor protein, p53, plays an important role in regulating the cellular response to DNA damage, we decided to investigate whether the DNA damage- induced L13 mRNA stability was dependent on p53, using HCT116 p53 wild type (p53 $\left.3^{+/}\right)$and its derivative cells lacking p53 $\left(\mathrm{p} 53^{-/}\right)$. We found that treatment with VP-16 increased the L13 mRNA stability in both cell lines, indicating that the L13 transcript is stabilized in cells containing DNA damage regardless of the status of the p53 gene (Fig. 1C).

Silencing of the L13 gene by small interference RNAs inhibits cell growth. To begin to address the functional importance of L13 in human cancer cells, we used siRNAs to decrease the expression of L13. The siRNAs used in these experiments were designed to be complementary to several regions of the corresponding mRNA, and each siRNA was synthesized and then screened for the ability to down-regulate L13 expression. We found that two sequences, si-L13-1 and si-L13-2, were effective at suppressing L13 expression, so they were used in subsequent experiments. An siRNA lacking sequence homology with any human gene was used as a control (si-cont). NUGC4 human stomach cancer cells were transfected with double-stranded siRNA oligonucleotides. Cells were harvested $48 \mathrm{~h}$ after transfection, and L13 expression was analyzed by RT-PCR. As shown in Fig. 2A, both L13 siRNA oligonucleotides effectively blocked L13 expression. Control siRNA had no effect on L13 expression. Although NUGC4 cells expressed negligible levels of L13 in cells exposed to L13 siRNAs, the expression of GAPDH mRNA was unaffected by the L13 or control siRNAs (Fig. 2A). We then evaluated the effects of decreased L13 expression on the growth of NUGC4 and HCT116 cells at different time-points by cell counting. As shown in Fig. 2B, siRNA targeting L13 suppressed the proliferation of both types of cells by more than $50 \%$ of the control value at the second day, and more extensively by day 4 (Fig. 2B). At the same time-points, however, no evidence of apoptosis was detected upon L13 silencing by siRNA, as judged by the lack of nuclear fragmentation (data not shown). We further analyzed the effect of L13 siRNA on cell cycle progression and showed that L13 silencing by siRNA caused a significant degree of cell cycle arrest, as indicated by the reduction of the number of cells in S phase (Fig. 2C). Fortyeight hours after transfection, $17 \%$ of si-L13-2-treated cells were in S phase compared with $36 \%$ of si-cont-treated cells (Fig. 2C). These data indicated an important role of L13 in cancer cell survival and growth.

We then investigated the role of L13 on chemosensitivity. Transfected cells were exposed in vitro to chemotherapeutic agents used to treat gastrointestinal malignancies, DOX, VP-16 and CDDP. Forty-eight hours later, chemosensitivity was measured using the MTT assay. We found that decreased expression of L13 resulted in increased cell sensitivity to chemotherapy (Fig. 2D). These data suggested that the cellular response to DNA damage could be greatly affected by L13knockdown.

Tumorigenicity of L13-silenced cancer cells. To further determine whether the observed inhibitory effects of the suppression of L13 on tumor cell proliferation in vitro could be demonstrated in an in vivo model, we tested the tumorigenic potential of L13-silenced cancer cells in nude mice. Viable NUGC4 cells $\left(2 \times 10^{6} /\right.$ mouse) transfected with either si-L13-2 or si-cont were subcutaneously injected into seven mice in each treatment 
A

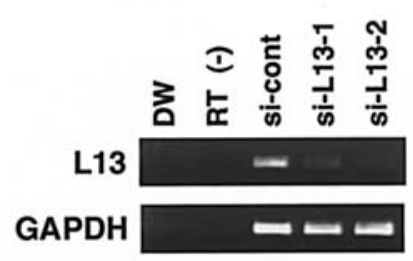

B

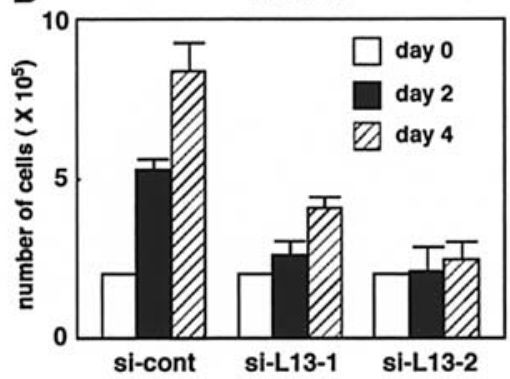

HCT116

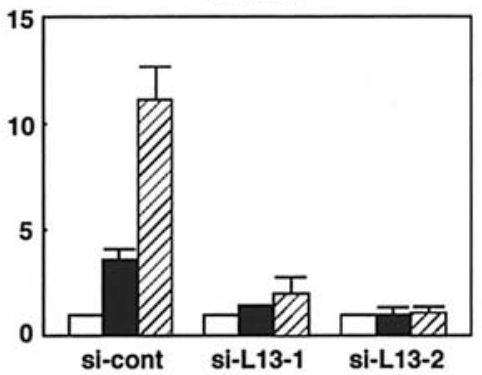

C

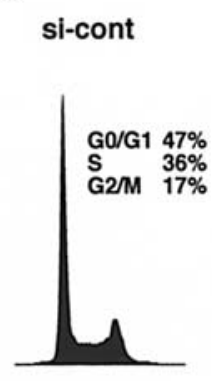

si-L13-1

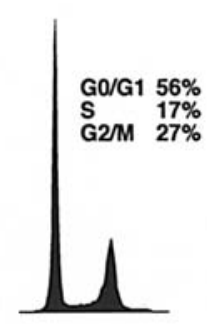

si-L13-2

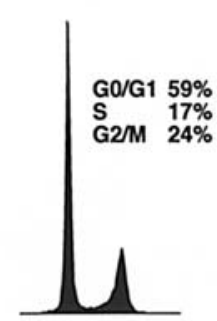

D

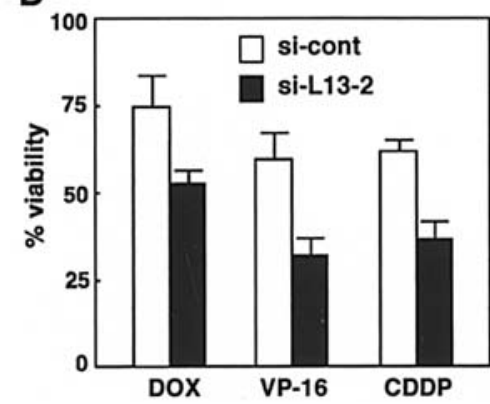

Figure 2. Impact of L13 siRNA on cell viability and cell cycle progression. (A) NUGC4 cells were transfected with L13 siRNA (si-L13-1 and si-L13-2) or control siRNA (si-cont). One day after transfection, suppression of L13 was determined by semi-quantitative RT-PCR. Expression of the GAPDH gene was examined as a quality control. Distilled water (DW) and total RNA untreated with reverse transcriptase [RT (-)] were used as negative controls. (B) The cell proliferation rate was measured by counting NUGC4 and HCT116 cells after L13 siRNA. Transfected cells ( $2 \times 10^{5}$ cells) were plated in T25 flasks. Live and dead cells were counted as triplicate cultures by trypan blue exclusion on the indicated days. Each point represents the mean and standard deviation of triplicate cultures. (C) Effect of L13 siRNA on cell cycle progression. NUGC4 cells were transfected with L13 siRNA or control siRNA. After 48 h, cells were trypsinized and then analyzed by flow cytometry. The percentages of cells in each phase of the cell cycle (G1, S and G2/M) are shown in the upper-right corner. Experiments were repeated three times, and representative results are shown. (D) L13 siRNA enhanced the chemosensitivity to DNA-damaging agents. NUGC4 cells were transfected with L13 or control siRNA and subsequently exposed to $0.2 \mu \mathrm{g} / \mathrm{ml}$ DOX, $10 \mu \mathrm{M}$ VP-16 or $20 \mu \mathrm{M}$ CDDP for $48 \mathrm{~h}$ prior to MTT analysis. MTT assays were performed in triplicate. Error bars equal one standard error.

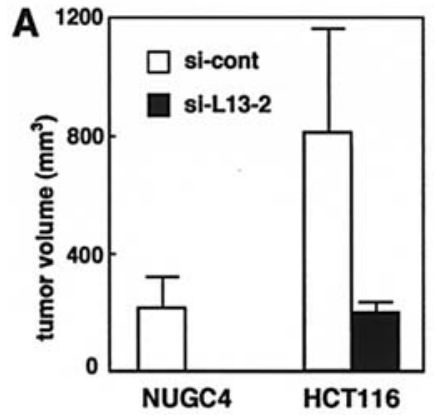

B

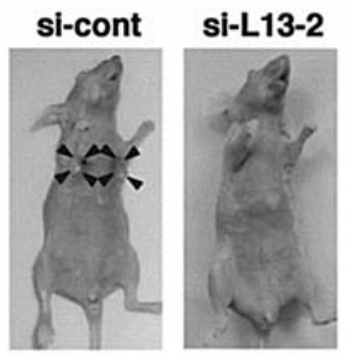

Figure 3. Decreased tumorigenicity of L13-silenced cancer cells in nude mice. (A) siRNA transfected cells $\left(2 \times 10^{6}\right.$ cells) were injected s.c. into each nude mouse. Mice were scored for tumor formation after 35 days. Results were reported as the mean $\pm \mathrm{SD}$ in seven mice for each treatment group. No tumors formed in any of the mice who received injections of NUGC4 cells that had been transfected with si-L13-2 for an extended period of 35 days. (B) Tumor formation in nude mice.

group. Tumors started to form around 10 days after injection and were observed in all mice who received injections of si-cont-transfected NUGC4 cells. Once tumors were established, they grew aggressively, ultimately reaching an average volume of about 200-300 $\mathrm{mm}^{3}$ within 4 weeks after injection. In contrast, no tumors formed in any of the mice who received injections of NUGC4 cells that had been transfected with si-L13-2 within the same periods of time, indicating that the tumorigenicity of NUGC4 cells was completely suppressed by L13 siRNA (Fig. 3). When nude mice were inoculated with HCT116 cells, the tumors grew more aggressively than those of NUGC4 cells, but the tumorigenicity of si-L13-2-transfected HCT116 cells was also significantly reduced compared with si-cont-transfected HCT116 cells (Fig. 3). These in vivo results correlate with the specificity observed in vitro.

L13 overexpression inhibits chemosensitivity. To further explore the potential oncogenic function of L13, we transiently overexpressed L13 in HepG2 hepatocellular carcinoma cells by transfecting them with a CMV-driven expression plasmid (pcDNA/His-L13). HepG2 was chosen because it has a readily detectable expression level of L13, albeit lower than that observed in most human cancer cell lines (data not shown). We also prepared control HepG2 cells transfected with the mock vector and compared their proliferation with that of L13-overexpressing HepG2 cells by cell counting. Western blot analysis confirmed that a dramatic increase in exogenous L13 protein level occurred as a result of transfection (Fig. 4A). Interestingly, L13 overexpression did not significantly alter the growth of HepG2 cells (Fig. 4B). 
A

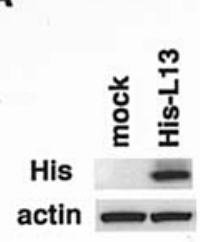

B

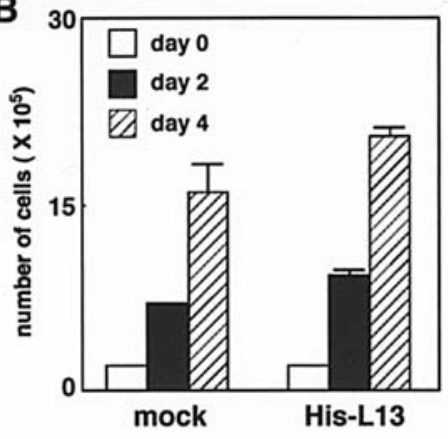

C

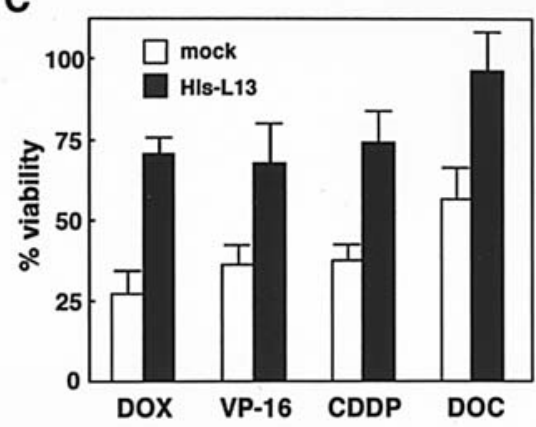

D

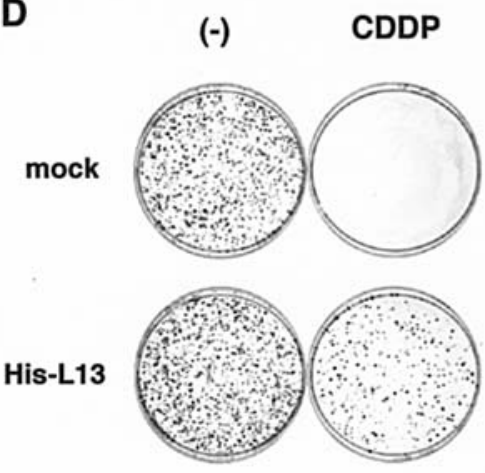

E

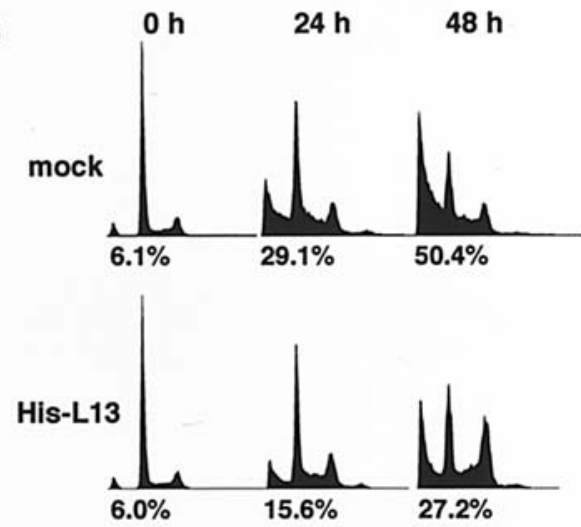

Figure 4. Ectopic L13 expression changes the chemosensitivity to DNA-damaging agents. (A) HepG2 human liver cancer cells were transfected with L13 expression plasmid (pcDNA/His-L13) or empty vector plasmid (mock). At $24 \mathrm{~h}$ after transfection, cell lysates were prepared, and the expression of His-L13 was detected by Western blotting using rabbit polyclonal antibodies to the His tag. (B) The cell proliferation rate was measured by counting HepG2 cells after L13 overexpression as described above. Each point represents the mean and standard deviation of triplicate cultures. (C) Transfected cells were exposed to $0.2 \mu \mathrm{g} / \mathrm{ml} \mathrm{DOX}, 10 \mu \mathrm{M} \mathrm{VP}-16,20 \mu \mathrm{M}$ CDDP or $1 \mu \mathrm{M}$ DOC for $48 \mathrm{~h}$, and survival was subsequently determined by MTT assay. Data are the means \pm SD from three independent experiments. (D) Colony formation assay of HepG2 cells transfected with L13 expression plasmid or empty vector plasmid. The transfected cells (5,000 cells) were plated in 6-cm tissue culture dishes. Twenty-four hours after plating, the cells were treated with $25 \mu \mathrm{M}$ VP-16 for $2 \mathrm{~h}$. After 2 weeks, colonies were fixed and stained with Giemsa stain. (E) Transfected cells were exposed to $20 \mu \mathrm{M}$ CDDP for the indicated number of hours. Cells were trypsinized, and then analyzed by flow cytometry. The percentage of cells in sub-G1 population is shown.

Because silencing of L13 by siRNA markedly increased chemosensitivity, we tested the effect of L13 overexpression on the degree of drug resistance in HepG2 cells using the MTT assay. Four chemotherapeutic agents, DOX, VP-16, CDDP and DOC, were used. As shown in Fig. 4C, the survival percentage of L13-overexpressing cells was significantly higher than that in mock cells after treatment with all four of the drugs. Similar experiments were performed to determine cell proliferation by colony formation assays. This method was chosen because it can quantify the cumulative cell death over a prolonged period. The same number of cells were plated at low density immediately after the second transfection of pcDNA/His-L13 or mock. After $24 \mathrm{~h}$, cells were treated for $1 \mathrm{~h}$ with $20 \mu \mathrm{M}$ CDDP. Colonies were stained and counted 14 days after treatment. As shown in Fig. 4D, L13 overexpression in HepG2 cells increased the survival of cells after CDDP treatment, as determined by colony-forming efficiency. These results further support the notion that a high level of L13 may confer resistance to chemotherapy.

We further investigated whether the increased chemoresistance of L13-overexpressing cells was due to a decrease in apoptosis. Transfected cells were treated with CDDP, after which the percentage of cells undergoing apoptosis was measured by FACS. As shown in Fig. 4E, in mock cells, 29.1 and $50.4 \%$ of cells died 24 and $48 \mathrm{~h}$, respectively, after treatment with CDDP but, in L13-overexpressing cells, 15.6 and $27.2 \%$ of cells died. These results indicate the potential of L13 to promote resistance of liver cancer cell lines to DNA damage-induced apoptosis.

L13 mRNA expression in gastrointestinal malignancies. Functional analysis implied that L13 was likely to be involved in carcinogenesis. We then assessed the expression of L13 mRNA in gastrointestinal cancer tissue samples by semiquantitative RT-PCR. Fig. 5 shows representative results of RT-PCR for L13. Up-regulation of L13 mRNA expression was observed in $10(28 \%)$ of 36 gastric, 19 (41\%) of 46 colorectal and $5(20 \%)$ of 25 liver cancer tissues compared with the expression in their matched normal tissue samples. The relationship between L13 expression and clinicopathological characteristics in gastric and colorectal cancers is shown in Tables I and II. L13 mRNA expression correlated with advanced stage in patients with gastric cancer. In colorectal cancer, there was a trend towards an association between upregulation of L13 mRNA expression and advanced stage, although these associations were not statistically significant. There was no correlation of L13 expression with histological type in gastric or colorectal cancer samples. In contrast, no 


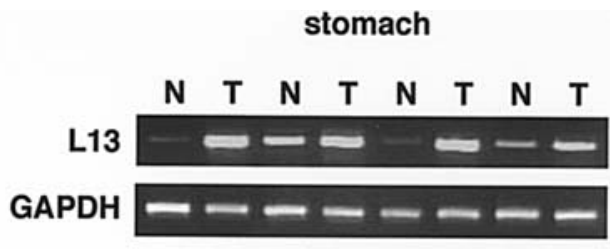

colorectal
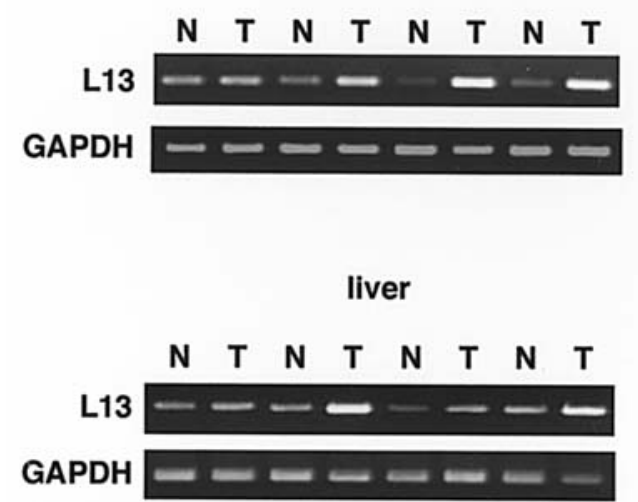

Figure 5. Representative RT-PCR results of L13 from primary gastric, colorectal and liver cancer tissues. Paired specimens of tumor and adjacent non-tumor tissues of the stomach, colorectum and liver were obtained from patients who had undergone surgical treatment. Up-regulation of L13 was judged when L13 gene expression in the tumor sample was at least three times higher than that in the corresponding normal sample. $N$ and $T$, matched samples from non-tumor and tumor tissue, respectively. significant association was found between up-regulation of L13 mRNA expression and clinicopathological characteristics including clinical staging, size of tumor, histological differentiation, and hepatitis B or C virus infection in liver cancer samples (data not shown).

\section{Discussion}

In this study, we focused on a novel stress-inducible gene, L13, as one of the transactivated genes in gastrointestinal cancer cells. We show that L13 expression is directly associated with the proliferation and survival of NUGC gastric and HCT116 colorectal cancer cells. Specific inhibition of L13 expression by siRNA tranfection resulted in a drastic reduction of cell growth (Fig. 2B). Although no evidence of apoptosis was seen after L13 silencing, the clearly decreased proliferation rate may be based on a direct effect on the cell cycle. In fact, we observed G1 and G2/M phase arrest in NUGC4 cells after L13 siRNA transfection (Fig. 2C). Additionally, to test the prolonged effects of temporary loss of L13 expression, we performed an in vivo tumorigenicity assay and showed that L13 silencing efficiently inhibited the tumorigenicity of cancer cells in nude mice (Fig. 3). The data suggest that decreased L13 expression imparted a possible long-term growth disadvantage on NUGC gastric and HCT116 colorectal cancer cells, which is rather surprising for a short-term gene knockdown approach such as siRNA. Given that most tissue culture cell lines have detectable L13 expression, it was of interest to

Table II. Relationship between expression of L13 mRNA and clinicopathological characteristics in gastric adenocarcinomas.

\begin{tabular}{|c|c|c|c|c|}
\hline \multirow[b]{2}{*}{ Variable } & \multirow[b]{2}{*}{ No. } & \multicolumn{2}{|c|}{ Expression of L13 mRNA (\%) } & \multirow[b]{2}{*}{ P-value } \\
\hline & & Increased & Non-increased & \\
\hline Total & 36 & $10(28)$ & $26(72)$ & \\
\hline \multicolumn{5}{|c|}{ Histological type } \\
\hline \multicolumn{5}{|c|}{ Laurren's classification } \\
\hline Intestinal & 18 & $5(28)$ & $13(72)$ & 1.000 \\
\hline Diffuse & 18 & $5(28)$ & $13(72)$ & \\
\hline \multicolumn{5}{|l|}{ Depth } \\
\hline $\mathrm{T} 1+\mathrm{T} 2$ & 13 & $3(23)$ & $10(77)$ & 0.636 \\
\hline $\mathrm{T} 3+\mathrm{T} 4$ & 23 & $7(30)$ & $16(70)$ & \\
\hline \multicolumn{5}{|c|}{ Node categories } \\
\hline N (-) & 10 & $1(10)$ & $9(90)$ & 0.140 \\
\hline $\mathrm{N}(+)$ & 26 & $9(35)$ & $17(65)$ & \\
\hline \multicolumn{5}{|c|}{ Metastasis categories } \\
\hline M (-) & 34 & $9(26)$ & $25(74)$ & 0.722 \\
\hline $\mathrm{M}(+)$ & 2 & $1(50)$ & $1(50)$ & \\
\hline \multicolumn{5}{|c|}{ Clinical stage } \\
\hline $\mathrm{I}+\mathrm{II}$ & 14 & $1 \quad(7)$ & $13(93)$ & 0.027 \\
\hline III+IV & 22 & $9(41)$ & $13(59)$ & \\
\hline
\end{tabular}

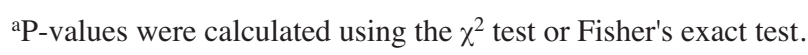


Table III. Relationship between expression of L13 mRNA and clinicopathological characteristics in colorectal adenocarcinomas.

\begin{tabular}{|c|c|c|c|c|}
\hline \multirow{3}{*}{$\begin{array}{l}\text { Variable } \\
\text { Total }\end{array}$} & \multirow{3}{*}{$\begin{array}{c}\text { No. } \\
46\end{array}$} & \multicolumn{2}{|c|}{ Expression of L13 mRNA (\%) } & \multirow{3}{*}{ P-value } \\
\hline & & \multirow{2}{*}{$\begin{array}{c}\text { Increased } \\
19(41)\end{array}$} & Non-increased & \\
\hline & & & $27 \quad(59)$ & \\
\hline \multicolumn{5}{|c|}{ Histological differentiation } \\
\hline Well & 3 & $1(33)$ & $2(67)$ & 0.617 \\
\hline Moderate & 34 & $13(38)$ & $21 \quad(62)$ & \\
\hline Poor & 9 & $5(56)$ & $4 \quad(44)$ & \\
\hline \multicolumn{5}{|l|}{ Depth } \\
\hline $\mathrm{T} 1+\mathrm{T} 2$ & 2 & $0 \quad(0)$ & $2(100)$ & 0.225 \\
\hline $\mathrm{T} 3+\mathrm{T} 4$ & 44 & $19(43)$ & $25 \quad(57)$ & \\
\hline \multicolumn{5}{|c|}{ Node categories } \\
\hline $\mathrm{N}(-)$ & 26 & $9(35)$ & $17 \quad(65)$ & 0.290 \\
\hline $\mathrm{N}(+)$ & 20 & $10(50)$ & $10 \quad(50)$ & \\
\hline \multicolumn{5}{|c|}{ Metastasis categories } \\
\hline M (-) & 41 & $16(39)$ & $25 \quad(61)$ & 0.368 \\
\hline $\mathrm{M}(+)$ & 5 & $3(60)$ & $2 \quad(40)$ & \\
\hline \multicolumn{5}{|l|}{ Dukes } \\
\hline A & 2 & $0 \quad(0)$ & $2(100)$ & 0.278 \\
\hline B & 27 & $10(37)$ & $17 \quad(63)$ & \\
\hline $\mathrm{C}$ & 17 & $9(53)$ & $8 \quad(47)$ & \\
\hline \multicolumn{5}{|c|}{ Clinical stage } \\
\hline $\mathrm{I}+\mathrm{II}$ & 27 & $8(30)$ & $19 \quad(70)$ & 0.055 \\
\hline III+IV & 19 & $11(58)$ & $8 \quad(42)$ & \\
\hline
\end{tabular}

aP-values were calculated using the $\chi^{2}$ test or Fisher's exact test.

assess the specificity of L13-dependent proliferation in a non-gastrointestinal cancer cell line.

In mammals, L13 was initially identified as the BBC1 gene, which is down-regulated in human malignant breast carcinomas as compared to benign breast fibroadenomas (36). The L13 gene is localized in the chromosome region, 16q24.3 (37), which was previously shown to be the LOH region in breast, prostate, gastric and liver cancers (37-45), suggesting that L13 may be a plausible candidate tumor suppressor gene. To test this possibility, we examined the mutational status of L13 cDNA in 30 gastrointestinal cancer cell lines. However, no mutations in the L13 gene were detected by direct sequencing. A previous study also reported that no L13 mutation was observed in breast carcinomas (31), which is consistent with our result. These findings imply that this gene is not a potential tumor-suppressor gene and that another gene at 16q24.3 must be a target for $\mathrm{LOH}$ in human cancers.

The present report also establishes a causal link between L13 and the response to DNA damage. Previous work from our laboratory demonstrated that L13 is up-regulated in $\mathrm{CHO}$ cells after treatment with chemotherapeutic drugs (16). In the present study, post-transcriptional regulation of L13 was studied in human cancer cells after exposure to DNA-damaging agents.
L13 transcript levels were measured following treatment with the transcriptional inhibitor, actinomycin D. After treatment with VP-16, L13 mRNA demonstrated an increased stability compared to untreated control cells, regardless of the status of the p53 gene, suggesting that post-transcriptional mechanisms may play a role in the regulation of L13 transcripts (Fig. 1). More importantly, we show that L13 may be associated with the defensive reaction mechanism of gastrointestinal cancer cells towards anticancer drugs: knockdown of L13 expression by siRNA significantly enhanced the cellular sensitivity to certain DNA-damaging agents (Fig. 2). Conversely, exogenous addition of L13 expression into cells inhibited chemosensitivity (Fig. 4). The destructive mechanisms of chemotherapy on cancer cells are mainly based on the generation of oxidative stress and/or induction of apoptosis (2). In our present study, we show that VP-16 as well as CDDP (both widely used therapeutic approaches for gastrointestinal cancer) lead to the induction of L13 in cancer cells. This underlines the role of L13 as a stress response gene, showing pronounced upregulation after first-time treatment, leading to the resistance to further therapy, a generally known clinical problem in cancer treatment. Although the molecular mechanism by which L13 induces chemoresistance is not yet clear, the inhibition 
of L13 expression may be an important approach to overcome the chemoresistance associated with gastrointestinal cancers.

We showed that L13 is up-regulated by genotoxic stress, and that basal L13 function may be necessary for the maintenance of tumor cell growth. The primary structures of ribosomal proteins are well conserved in eukaryotes. L13 is located in the large subunit of ribosomes and is one of 79 ribosomal proteins. To date, L13 homologues have been isolated in a wide range of species, including plants, yeast and animals (46-48). Bertauche et al showed that the expression of Arabidopsis thaliana L13 homologue, AtBBC1, positively correlated with active cell division (47). Moreover, the Drosophila melanogaster, L13, is expressed at all stages of development, with the highest levels occurring during embryogenesis (48). These findings are consistent with it being a ribosomal protein, since the levels of transcription and translation are relatively high in growing cells $(49,50)$. Considering the above findings together with our result showing that silencing L13 by siRNA inhibits cancer cell growth, it seems that the expression levels of L13 genes correlate with active cell division and cell growth.

Reports have also been published that observed the altered expression of some ribosomal proteins in human cancers (21-25). The present study is the first to compare L13 mRNA expression levels in tumor versus normal tissue; it demonstrated that the level of L13 mRNA was higher in $28 \%$ of gastric, $41 \%$ of colorectal and $20 \%$ of liver cancer tissues. Remarkably, these changes were frequently found in patients with advancedstage gastric cancer. Support for this finding came from a search in the CGAP based on serial analysis of gene expression, showing that the relative expression of L13 was higher in human stomach and colon cancer tissues compared with normal tissues. We also investigated the functional role of L13 expression in gastrointestinal cancer and found that L13 has significant influence on cancer cell growth. Although production of an antibody that specifically recognizes L13 will be important for confirming the expression of L13 in cancer cells at the protein level, our results indicate that L13 may be a novel target for diagnostic and therapeutic applications. Further investigations of the activation pathway of L13 and its cellular localization during the cell cycle in mammalian cells will facilitate a better understanding of the role of L13 in tumorigenesis.

The molecular mechanism whereby L13 is involved in cancer cell growth is not yet clear. The ribosome complex is essential for protein biosynthesis and consists of a large number of ribosomal proteins and rRNAs. Although the precise structure, functional role, and regulation of individual ribosomal proteins are largely unknown, studies of yeast mutants have revealed that some ribosomal proteins are essential for cell viability. It has been shown that these proteins have extraribosomal functions apart from ribosome and protein biosynthesis, including induction of apoptosis $(51,52)$, regulation of development (53), and DNA repair (54-56). Our findings suggest an extraribosomal function of L13. The amino acid sequence of human L13 contains two bipartite nuclear localization signals and a transactivation domain, highly conserved in other eukaryotic L13 proteins (57). Moreover, specific functions in transcription have been reported for ribosomal proteins S10 (58), L4 (59) and S14 (60). Thus, it is possible that L13 alters the transcription or translation of cell deathrelated gene products that we have not measured. Further experimental approaches are required for a full understanding of the function of L13 protein.

In conclusion, this study demonstrated that it is very likely that L13 plays a significant role in cancer cell viability. High L13 levels in gastrointestinal cancer cells may, at least partly, be responsible for their resistance to anticancer therapy. Furthermore, L13 may act as an endogenous protection mechanism, which potentially makes cancer cells more resistant to apoptotic stimuli, thus providing a growth advantage. Our results indicate that L13 is a novel target for diagnostic and therapeutic applications in gastrointestinal cancer.

\section{Acknowledgements}

This research was supported in part by Grants-in-Aid for Scientific Research on Priority Areas from the Ministry of Education, Culture, Sports, Science and Technology of Japan.

\section{References}

1. Greenlee RT, Murray T, Bolden S and Wingo PA: Cancer statistics, 2000. CA Cancer J Clin 50: 7-33, 2000.

2. Kaufmann SH and Vaux DL: Alterations in the apoptotic machinery and their potential role in anticancer drug resistance. Oncogene 22: 7414-7430, 2003.

3. Shah MA and Schwartz GK: Cell cycle-mediated drug resistance: an emerging concept in cancer therapy. Clin Cancer Res 7: 2168-2181, 2001

4. Martin SJ and Green DR: Apoptosis as a goal of cancer therapy. Curr Opin Oncol 6: 616-621, 1994.

5. Zunino F, Perego P, Pilotti S, Pratesi G, Supino R and Arcamone F: Role of apoptotic response in cellular resistance to cytotoxic agents. Pharmacol Ther 76: 177-185, 1997.

6. Meyn MS: Ataxia-telangiectasia and cellular responses to DNA damage. Cancer Res 55: 5991-6001, 1995.

7. Bunz F, Hwang PM, Torrance C, et al: Disruption of p53 in human cancer cells alters the responses to therapeutic agents. J Clin Invest 104: 263-269, 1999.

8. Stewart ZA, Westfall MD and Pietenpol JA: Cell-cycle dysregulation and anticancer therapy. Trends Pharmacol Sci 24: 139-145, 2003.

9. Iliakis G, Wang Y, Guan J and Wang H: DNA damage checkpoint control in cells exposed to ionizing radiation. Oncogene 22: 5834-5847, 2003.

10. Kastan MB, Onyekwere O, Sidransky D, Vogelstein B and Craig RW: Participation of p53 protein in the cellular response to DNA damage. Cancer Res 51: 6304-6311, 1991.

11. El-Deiry WS: Regulation of p53 downstream genes. Semin Cancer Biol 8: 345-357, 1998.

12. Tokino $\mathrm{T}$ and Nakamura $\mathrm{Y}$ : The role of p53-target genes in human cancer. Crit Rev Oncol Hematol 33: 1-6, 2000.

13. Toyota M, Sasaki Y, Satoh A, et al: Epigenetic inactivation of CHFR in human tumors. Proc Natl Acad Sci USA 100: 7818-7823, 2003.

14. Satoh A, Toyota M, Itoh F, et al: Epigenetic inactivation of CHFR and sensitivity to microtubule inhibitors in gastric cancer. Cancer Res 63: 8606-8613, 2003.

15. Ikeda H, Sasaki Y, Kobayashi T, et al: The role of T-fimbrin in the response to DNA damage: silencing of T-fimbrin by small interfering RNA sensitizes human liver cancer cells to DNAdamaging agents. Int J Oncol 27: 933-940, 2005

16. Sasaki Y, Itoh F, Suzuki H, Kobayashi T, Kakiuchi H, Hareyama $\mathrm{M}$ and Imai $\mathrm{K}$ : Identification of genes highly expressed in G2-arrested Chinese hamster ovary cells by differential display analysis. J Clin Lab Anal 14: 314-319, 2000.

17. Sasaki Y, Itoh F, Kobayashi T, Kikuchi T, Suzuki H, Toyota M and Imai $\mathrm{K}$ : Increased expression of T-fimbrin gene after DNA damage in $\mathrm{CHO}$ cells and inactivation of $\mathrm{T}$-fimbrin by $\mathrm{CpG}$ methylation in human colorectal cancer cells. Int J Cancer 97: 211-216, 2002. 
18. Wool IG: Extraribosomal functions of ribosomal proteins. Trends Biochem Sci 21: 164-165, 1996.

19. Chen FW and Ioannou YA: Ribosomal proteins in cell proliferation and apoptosis. Int Rev Immunol 18: 429-448, 1999.

20. Draptchinskaia N, Gustavsson P, Andersson B, et al: The gene encoding ribosomal protein S19 is mutated in Diamond-Blackfan anaemia. Nat Genet 21: 169-175, 1999.

21. Chester KA, Robson L, Begent RH, et al: Identification of a human ribosomal protein mRNA with increased expression in colorectal tumours. Biochim Biophys Acta 1009: 297-300, 1989.

22. Chiao PJ, Shin DM, Sacks PG, Hong WK and Tainsky MA: Elevated expression of the ribosomal protein S2 gene in human tumors. Mol Carcinog 5: 219-231, 1992.

23. Barnard GF, Staniunas RJ, Mori M, Puder M, Jessup MJ, Steele GD Jr and Chen LB: Gastric and hepatocellular carcinomas do not overexpress the same ribosomal protein messenger RNAs as colonic carcinoma. Cancer Res 53: 4048-4052, 1993.

24. Pogue-Geile K, Geiser JR, Shu M, Miller C, Wool IG, Meisler AI and Pipas JM: Ribosomal protein genes are overexpressed in colorectal cancer: isolation of a cDNA clone encoding the human S3 ribosomal protein. Mol Cell Biol 11: 3842-3849, 1991.

25. Nadano D, Notsu T, Matsuda T and Sato T: A human gene encoding a protein homologous to ribosomal protein L39 is normally expressed in the testis and derepressed in multiple cancer cells. Biochim Biophys Acta 1577: 430-436, 2002.

26. Horiuchi S, Yamamoto H, Min Y, Adachi Y, Itoh F and Imai K: Association of ets-related transcriptional factor E1 AF expression with tumour progression and overexpression of MMP-1 and matrilysin in human colorectal cancer. J Pathol 200: 568-576, 2003.

27. Taniguchi H, Yamamoto H, Hirata T, et al: Frequent epigenetic inactivation of Wnt inhibitory factor-1 in human gastrointestinal cancers. Oncogene 24: 7946-7952, 2005.

28. Sobin LH and Fleming ID: TNM Classification of Malignant Tumors. 5th edition. Union Internationale Contre le Cancer and the American Joint Committee on Cancer. Cancer 80: 18031804, 1997.

29. Laur'en P: The two histological main types of gastric carcinoma: diffuse and so-called intestinal-type carcinoma. An attempt at a histo-clinical classification. Acta Pathol Microbiol Scand 64: 31-49, 1965.

30. Dukes E: The classification of cancer on the rectum. J Pathol Bacteriol 35: 323-332, 1932

31. Moerland E, Breuning MH, Cornelisse CJ and Cleton-Jansen AM: Exclusion of $\mathrm{BBC} 1$ and $\mathrm{CMAR}$ as candidate breast tumoursuppressor genes. Br J Cancer 76: 1550-1553, 1997.

32. Sasaki Y, Ishida S, Morimoto I, et al: The p53 family member genes are involved in the Notch signal pathway. J Biol Chem 277: 719-724, 2002.

33. Sasaki Y, Morimoto I, Ishida S, Yamashita T, Imai K and Tokino T: Adenovirus-mediated transfer of the p53 family genes, p73 and p51/p63 induces cell cycle arrest and apoptosis in colorectal cancer cell lines: potential application to gene therapy of colorectal cancer. Gene Ther 8: 1401-1408, 2001.

34. Sasaki Y, Mita H, Toyota M, et al: Identification of the interleukin 4 receptor alpha gene as a direct target for p73. Cancer Res 63: 8145-8152, 2003

35. Hugel A and Wernert N: Loss of heterozygosity (LOH), malignancy grade and clonality in microdissected prostate cancer. Br J Cancer 79: 551-557, 1999.

36. Adams SM, Helps NR, Sharp MG, Brammar WJ, Walker RA and Varley JM: Isolation and characterization of a novel gene with differential expression in benign and malignant human breast tumours. Hum Mol Genet 1: 91-96, 1992.

37. Cleton-Jansen AM, Moerland EW, Kuipers-Dijkshoorn NJ, et al: At least two different regions are involved in allelic imbalance on chromosome arm 16q in breast cancer. Genes Chromosomes Cancer 9: 101-107, 1994.

38. Lindblom A, Rotstein S, Skoog L, Nordenskjold M and Larsson C: Deletions on chromosome 16 in primary familial breast carcinomas are associated with development of distant metastases. Cancer Res 53: 3707-3711, 1993

39. Dorion-Bonnet F, Mautalen S, Hostein I and Longy M: Allelic imbalance study of $16 \mathrm{q}$ in human primary breast carcinomas using microsatellite markers. Genes Chromosomes Cancer 14: $171-181,1995$
40. Carter BS, Ewing CM, Ward WS, et al: Allelic loss of chromosomes $16 \mathrm{q}$ and $10 \mathrm{q}$ in human prostate cancer. Proc Natl Acad Sci USA 87: 8751-8755, 1990 .

41. Cleton-Jansen AM, Moerland HW, Callen DF, Doggett NA, Devilee P and Cornelisse CJ: Mapping of the breast basic conserved gene (D16S444E) to human chromosome band 16q24.3. Cytogenet Cell Genet 68: 49-51, 1995.

42. Latil A, Cussenot O, Fournier G, Driouch K and Lidereau R: Loss of heterozygosity at chromosome $16 \mathrm{q}$ in prostate adenocarcinoma: identification of three independent regions. Cancer Res 57: 1058-1062, 1997

43. Tsuda H, Zhang WD, Shimosato Y, et al: Allele loss on chromosome 16 associated with progression of human hepatocellular carcinoma. Proc Natl Acad Sci USA 87: 6791-6794, 1990

44. Fujimori M, Tokino T, Hino O, et al: Allelotype study of primary hepatocellular carcinoma. Cancer Res 51: 89-93, 1991.

45. Piao Z, Park C, Kim JJ and Kim H: Deletion mapping of chromosome 16q in hepatocellular carcinoma. Br J Cancer 80: 850-854, 1999.

46. Saez-Vasquez J, Raynal M, Meza-Basso L and Delseny M: Two related, low-temperature-induced genes from Brassica napus are homologous to the human tumour bbc1 (breast basic conserved) gene. Plant Mol Biol 23: 1211-1221, 1993.

47. Bertauche N, Leung J and Giraudat J: Conservation of the human breast basic conserved 1 gene in the plant kingdom: characterization of a cDNA clone from Arabidopsis thaliana. Gene 141: 211-214, 1994

48. Helps NR, Adams SM, Brammar WJ and Varley JM: The Drosophila melanogaster homologue of the human BBC1 gene is highly expressed during embryogenesis. Gene 162: 245-248, 1995.

49. Kief DR and Warner JR: Coordinate control of syntheses of ribosomal ribonucleic acid and ribosomal proteins during nutritional shift-up in Saccharomyces cerevisiae. Mol Cell Biol 1: 1007-1015, 1981

50. Tushinski RJ and Warner JR: Ribosomal proteins are synthesized preferentially in cells commencing growth. J Cell Physiol 112: $128-135,1982$

51. Naora H, Takai I, Adachi M and Naora H: Altered cellular responses by varying expression of a ribosomal protein gene: sequential coordination of enhancement and suppression of ribosomal protein S3a gene expression induces apoptosis. J Cell Biol 141: 741-753, 1998.

52. Neumann F and Krawinkel U: Constitutive expression of human ribosomal protein L7 arrests the cell cycle in G1 and induces apoptosis in Jurkat T-lymphoma cells. Exp Cell Res 230: 252-261, 1997.

53. Van Lijsebettens M, Vanderhaeghen R, De Block M, Bauw G, Villarroel R and van Montagu M: An S18 ribosomal protein gene copy at the Arabidopsis PFL locus affects plant development by its specific expression in meristems. Embo J 13: 3378-3388, 1994.

54. Kim J, Chubatsu LS, Admon A, Stahl J, Fellous R and Linn S: Implication of mammalian ribosomal protein $\mathrm{S} 3$ in the processing of DNA damage. J Biol Chem 270: 13620-13629, 1995.

55. Lim Y, Lee SM, Kim M, Lee JY, Moon EP, Lee BJ and Kim J: Complete genomic structure of human rpS3: identification of functional U15b snoRNA in the fifth intron. Gene 286: 291-297, 2002.

56. Wilson DM III, Deutsch WA and Kelley MR: Drosophila ribosomal protein S3 contains an activity that cleaves DNA at apurinic/apyrimidinic sites. J Biol Chem 269: 25359-25364, 1994.

57. Jain M, Tyagi SB, Thakur JK, Tyagi AK and Khurana JP: Molecular characterization of a light-responsive gene, breast basic conserved protein 1 (OsiBBC1), encoding nuclear-localized protein homologous to ribosomal protein L13 from Oryza sativa indica. Biochim Biophys Acta 1676: 182-192, 2004.

58. Mason SW, Li J and Greenblatt J: Direct interaction between two Escherichia coli transcription antitermination factors, NusB and ribosomal protein S10. J Mol Biol 223: 55-66, 1992.

59. Zengel JM and Lindahl L: Ribosomal protein L4 stimulates in vitro termination of transcription at a NusA-dependent terminator in the S10 operon leader. Proc Natl Acad Sci USA 87: 2675-2679, 1990

60. Tasheva ES and Roufa DJ: Regulation of human RPS14 transcription by intronic antisense RNAs and ribosomal protein S14. Genes Dev 9: 304-316, 1995. 